\title{
The differences between Danish determiner and quantity genitives: The essential data set ${ }^{1}$
}

\author{
Per Anker Jensen † \\ Copenhagen Business School
}

\begin{abstract}
This paper presents the set of essential syntactic and semantic data pertaining to Danish determiner genitives like Bos gode digt ('Bo's good poem'), measure genitives like to timers hård sejlads ('two hours' tough sailing') and constitutive genitives like to retters loekker menu ('two courses' delicious menu)'. The two latter genitive types are both subtypes of the class of quantity genitives. I lay out a chart of Danish pre-nominal genitives and justify the inclusion of each type and its position in the chart. In a detailed table, the differences are characterised and exemplified to make comparison possible and contrasts transparent. Finally, I discuss a number of issues concerning definiteness, pronominalization, constituency and cliticization raised by a DP-analysis of determiner genitives proposed by Sten Vikner. Since we are still far from understanding the full landscape of Danish genitives syntactically as well as semantically, the aim of this paper is to offer an accurate description of the data in order that the creation of a coherent theory of Danish genitives may be thereby facilitated.
\end{abstract}

\section{Methodological preliminaries}

The first major work to explore and explicate generative syntax was Chomsky's The Logical Structure of Linguistic Theory in the mid-1950s. ${ }^{2}$ Three interdependent goals were set up: First, the construction of grammars for particular languages; second, the construction of an abstract theory of

1 My heart-felt thanks are due to professor emeritus Robert E.Wall, UT Austin, for reading and discussing the paper with me.

Later published as Chomsky 1975.

Ken Ramshøj Christensen, Henrik Jørgensen \& Johanna L. Wood (eds.). 2019.

The Sign of the V-Papers in Honour of Sten Vikner. Dept. of English, School of Communication \& Culture, Aarhus University, pp. 285-309, doi:10.7146/aul.348.1100. (C) The author(s). 
linguistic structure; thirdly, and most ambitiously, the so-called level of "justification of grammars", understood as an explanatory theory of why grammars of natural languages have the exact properties they do (see Chomsky 1975, §3; Chomsky 1964, ch.2; Chomsky 1965, §§4-7). At the lowest level of linguistic description, the focus is on the accurate rendition of the facts pertaining to the language under scrutiny. However, since the three goals are supposed to be systematically intertwined, in principle, the description suggested for the particular language should be in compliance with some abstract theory of linguistic structure, e.g. - to take a long leap to our present day and age - a version of Principles and Parameters theory (P\&P).

This paper operates between the two lowest levels, in Chomsky (1964, ch.2; Rizzi, 2016) termed the levels of "observational adequacy" and "descriptive adequacy", respectively. My description transcends "observational adequacy" in that this level does not take into account syntactic structure, but aims only at generating the exact set of strings belonging to the language. The reason why I do not reach the level of "descriptive adequacy", is that this level should capture the structures matching native-speaker intuitions. This, of course, requires a full theory of the language, which is exactly what we do not have. So, what I do offer is a, hopefully, accurate rendition of the observable syntactic and semantic facts pertaining to a theoretically challenging fragment of Danish grammar covering the two major types of pre-nominal genitives, determiner genitives like those in ) and quantity genitives like those in ):
(1) Bos mand
'Bo's husband'
(2) to retters menu
two courses.GEN menu
'two course menu'

I staunchly support Chomsky's (1957: 5) call for "precisely constructed models for linguistic structure". But let me add a quote from Otto Jespersen, which pre-dates Chomsky by almost two decades:

[...] the complexity of human language and thought is clearly brought before one when one tries to get behind the more or less accidental linguistic forms in order to penetrate to their notional kernel. Much that we are apt to take for granted in everyday speech and consider as 
simple or unavoidable discloses itself on being translated into symbols as a rather involved logical process [...] (Jespersen, 1937: 15).

It seems fair to say that Jespersen was an early proponent of using formal representations in linguistic description, both with respect to individual languages and as a possible basis for cross-linguistic comparison. His formalisations were not mathematically well-defined as he emphasizes himself, cf. his use of italics in the following quote: "[My system] cannot pretend to the same degree of universality as either the chemical or mathematical symbols [...] because of the fact, which it is no use shirking, that language is everywhere socially conditioned" (Jespersen, 1937: 1314). This brings to light the immense difference between the perspectives from which Jespersen and Chomsky each perceive human language. There is absolutely no universalism in Jespersen's philosophy of language ${ }^{3}$, whereas universalism is at the very heart of Chomsky's.

I am a universalist in Chomsky's sense. What I borrow from Jespersen, however, is his insistence on establishing systematic correlations between the "notional kernel" and "the more or less accidental linguistic forms". Jespersen's efforts to make syntax and semantics come together in a systematic way is a far cry from chomskyan linguistics and much more in the vein of modern non-transformational, monostratal, sign-based, formal linguistic theories like GPSG, HPSG and LFG, whose express aim was - and is, insofar as the theory is still around - to have a formally welldefined syntax support an explicit, compositional formal semantics. GPSG is now extinct, but the authors' remarks on universals, the syntax/semantics interface and methodology are still very important, see Gazdar et al. (1985: 1-12) and the discussion of the status of semantic compositionality as a part of the Faculty of Language in Del Pinal (2015). For the same reason, the notionally grounded syntactic analysis of another Danish grammarian, Kristian Mikkelsen (1911), will play a central role in the data presentation and the arguments concerning the DP-analysis in section 5.

The structure of the paper is as follows: Section 2 introduces the crucial syntactic test for distinguishing determiner genitives from quantity genitives. Section 3 presents a chart exhibiting the subtypes of the two types of genitives, and each subtype is briefly described. Section 4 details the comprehensive data set distinguishing the two genitive types syntactically

3 See Jespersen's remarks on universal grammar and grammatical categories in Jespersen (1924: 46-53). 
as well as semantically, and the semantic differences between measure and constitutive genitives are laid out as well. Sections 5 and 6 discuss selected aspects of Sten Vikner's attempts to capture the syntax of Danish determiner genitives in a DP-analysis. Finally, section 7 summarizes and concludes my deliberations.

\section{The two main types of Danish pre-nominal genitives}

Determiner and quantity genitives are readily told apart by a syntactic test whereby an attributive AP is inserted after the genitive morpheme in each case, cf. the acceptability patterns in (3) and ):

(3) Determiner Genitive (DG)
a. Bos ven
'Bo's friend'
b. *Bos god
Bo's $\operatorname{good}_{\text {[SG; INDEFINITE] }}$
c. Bos gode
Bo's $\operatorname{good}_{[\mathrm{SG} ; \mathrm{DEFINITE}]} \quad$ friend
ven
friend
ven

(4) Quantity Genitive (QG)
a. to timer $-\mathrm{s}$ sejlads
'two hours' sailing'
b. to timer $-\mathrm{s}$ god sejlads
two hours' $\operatorname{good}_{\text {[SG;INDEFINITE] }} \quad$ sailing
c. * to timer -s gode sejlads
two hours' $\quad \operatorname{good}_{[\mathrm{SG} ; \mathrm{DEFINITE}]}$ sailing

The examples in ) illustrate the mandatory definite form of attributive APs in DGs, cf. the AP head gode in c), whereas QGs require the indefinite form god, as seen in b). For all genitives, this test is sufficient to establish whether they belong to a subtype of the category DG or of the category QG. However, there are a considerable number of other syntactic and semantic differences between the two genitive types as explained in sections 3 and 4 below.

\section{A chart of Danish pre-nominal genitives}

Having established the crucial syntactic difference between DGs and QGs, we can now present a "chart" of Danish pre-nominal genitives, cf. ): 
$(5)^{4}$

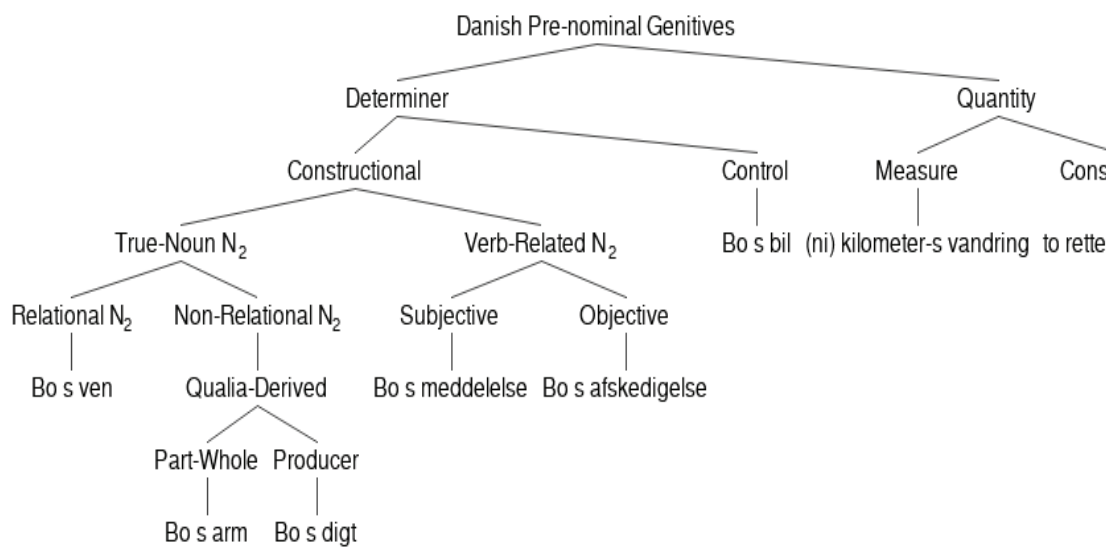

I shall refer to the $\{\mathrm{s}\}$-morphemes of the two genitive types as "DG $s$ " and "QG $-s$ ", respectively. ${ }^{5}$ I take DG $s$ to be a free, clitic lexeme, which is why (contrary to the written Danish convention) I occasionally write it as a separate item as in Bo s bil ('Bo s car') instead of Bos bil. The QG to retters menu ('two courses' menu') is, theoretically speaking, correctly written with $-s$ as part of the preceding noun to which it mandatorily attaches.

As should be immediately evident from the chart in ), most of the designations of subtypes have a semantic rather than a syntactic basis. This is owing to the fact that all DGs share the same syntactic structure, as do all QGs. The syntactic structure of QGs, however, is arguably completely different from that of DGs (cf. Jensen, 2017). We shall now look at the two types in turn.

Determiner genitives. Under the category of DGs on the top left-hand branch of the chart, the major split is between 'constructional' interpretations

4 English glosses for the phrases at the leaves of the chart from left to right: 'Bo's friend'; 'Bo's arm'; 'Bo's poem'; 'Bo’s announcement'; 'Bo's sacking'; 'Bo's car'; '(nine) kilometres' hiking'; 'two courses' menu'. The parentheses around ni in the QG (ni) kilometer-s vandring indicate optionality of the quantifier, which is an important feature distinguishing measure genitives from constitutive genitives, cf. item 12 in Table 1.

5 Throughout the paper, it is therefore important to notice the notation conventions not only between the two genitive forms DG $s$ and QG $-s$, but also the abbreviations 'DGs' and 'QGs', which respectively abbreviate the plural forms 'determiner genitives' (i.e. a full phrase like en digter $s$ vark ('a poet's work')), and 'quantity genitives' (i.e. a full phrase like to retter s menu ('two courses' menu')). 
and 'control' interpretations. This distinction builds on the hypothesis that the 'genitive relation', which is always understood but never explicit in genitive constructions, has different origins in the DGs. The control relation seems to originate from $s$ itself, since, in an example like $B o s$ bil ('Bo's car') it seems not to be available from either Bo or bil. Thus, $s$ looks like the only possible lexical source. For a more detailed elaboration of the concept of 'control', see Jensen \& Vikner (2004, section 3.5.1). In constructional $\mathrm{DGs}^{6}$, on the other hand, the genitive relation does not come from $s$. Instead, it is picked up from the meaning provided by the nominal following $s$ (henceforth, ' $\mathrm{N}_{2}$ ') in the genitive construction. For relational true nouns ${ }^{7}$, such as ven ('friend') in Bo s ven, this hypothesis works fairly well since a relation is immediately available from the argument structure of the head noun of the construction.

To all intents and purposes, the same holds for genitive constructions with nominal heads derived from verbs, e.g. Bo s meddelelse ('Bo's announcement'), where meddelelse is derived from the verb meddele ('announce') and Bo s afskedigelse ('sacking'), where afskedigelse is derived from the verb afskedige ('sack', 'fire', 'lay off'), and where the derived nominal inherits the relation expressed by the verb stem. In all of these cases, the semantic function of the nominal preceding DG $s$ (henceforth, ' $\mathrm{N}_{1}$ ') is to provide a semantic argument for the genitive relation.

Relational interpretations of non-relational (sortal) true nouns like arm ('arm') and digt ('poem') come about in a more indirect manner. As suggested by Jensen \& Vikner (1994) and elaborated in Vikner \& Jensen (2002), information about salient relations into which the referents of such nouns enter, may be picked up from the qualia structure of $\mathrm{N}_{2}$. In the chart, this type of genitive interpretation is therefore designated 'QualiaDerived'. ${ }^{8}$ Empirical investigations into qualia-derived interpretations (see Jensen \& Vikner, 2004) show that especially the part-whole and the producer interpretations provided by the Constitutive and the Agentive

6 The term 'constructional' was suggested by Barbara Partee, see also Borschev \& Partee (2000: 179, 192).

7 My use of the term "relational noun" is the one proposed by Löbner (2011: 2): "Relational nouns are binary predicate terms of type $\langle\mathrm{e},\langle\mathrm{e}, \mathrm{t}\rangle\rangle$. Their meanings are binary relational concepts, involving a further argument in addition to the referential argument. Relational nouns characterize their referents in terms of a particular relation to some other object. [...] this object is usually specified by means of a possessive construction." See Pustejovsky (1995) for the concept of 'qualia structure'. 
roles, respectively, are relevant to the semantics of DGs. An explanation of why the Telic role does not seem to come into play in semantic ${ }^{9}$ genitive interpretations (contrary to what is claimed in Jensen \& Vikner 1994) is unavailable even today.

The above brief review of interpretations of constructional and control genitives exhausts the DG categories mentioned in the chart. However, a number of other subtypes have not been included even though they clearly belong with the DGs. ${ }^{10}$ The reason is that they cannot be straightforwardly incorporated into the analysis of constructional genitives presented above, which relies crucially on the availability of a relation from $\mathrm{N}_{2}$ and a semantic argument delivered by $\mathrm{N}_{1}$. One of these subtypes is genitives with a time-denoting $\mathrm{N}_{1}$ :

$\begin{array}{ll}\text { (6) dagen s } & \text { avis } \\ \text { day-the } G E N & \text { paper } \\ \text { 'today's paper' } & \end{array}$

Jensen \& Vikner (2004) proposes an analysis of these appealing to the concept of 'temporal trace' introduced by Krifka (1989). That is, "If $e$ is an eventuality, the temporal trace of $e$ is the time interval occupied by $e$ ". ${ }^{11}$ In examples like ), the temporal element seems to me to relate to some qualiaretrievable relation like the producer-relation 'publish' obtainable from the Agentive role of avis, where the $\mathrm{N}_{1}$ dagen anchors the time reference of the publishing/printing event. Further research is needed here.

Another subtype of DGs which does not fit into the interpretation pattern above, is illustrated in ):

(7) Danmark s rige

Denmark GEN realm

'the kingdom of Denmark'

For a recent treatment of this type in languages other than Danish, see Sæbø (2018).

\footnotetext{
9 The distinction I am making here between "semantic" or "lexical" interpretations on the one hand and "pragmatic interpretations" on the other is due to Briscoe et al. (1990: 4243).

${ }^{10}$ For the full range of DGs, see Mikkelsen (1911: 162-63) and Jensen (2014).

${ }^{11}$ For the formalization of the temporal trace function, see Krifka (1989: 97).
} 
Quantity genitives. The category of QGs on the top right-hand branch of the chart comprises the two subtypes 'measure genitives' and 'constitutive genitives', which share the exact same syntax, totally different from that of DGs. According to Hansen \& Heltoft $(2011: 436)^{12}$, the syntactic role of DG $s$ is to rankshift a nominal (indeed, a full DP) from its nominal function to determiner function. Following their analysis, Jensen (2017: 57) argues that the syntactic function of QG $-s$ is to rankshift NPs like to meter ('two metres') or to retter ('two courses') to the syntactic function of attributive APs. In both cases of rankshifting, of course, the consequences for the semantics of the two genitive types are considerable. Indeed, the semantics of QGs differs from that of DGs exactly as radically as the semantics of attributive adjectives differs from that of determiners. In formal semantic terms, the function of QG $-s$ is to typeshift the denotation of a nominal (a property of type $<\mathrm{e}, \mathrm{t}>$ ) into the denotation of an attributive AP (i.e. a function from a property to a property, that is, the type $<<\mathrm{e}, \mathrm{t}\rangle,<\mathrm{e}, \mathrm{t}>>)$. This is what happens semantically when one conjoins the meaning of an attributive AP and the nominal it modifies; for instance, 'pretty' is a property and 'girl' is a property; if these properties are conjoined, one gets the property 'pretty (and) girl'. This is roughly similar to what happens when a property like 'length_in_metres_equal to 2' is conjoined with a property like 'fishing rod' to get 'two metres long (and) fishing rod'.

Both measure genitives (MGs) and constitutive genitives (CGs) contribute to the full meaning of the construction with a quantity interpretation. However, while MGs ascribe a numerical value to a lexically determined parameter like length, height, weight, etc., CGs are quite different due to their additional meronymical semantics. CGs specify a value indicating the number of part-items to which $\mathrm{N}_{1}$ refers; for instance, in the example en to retters menu ('a two courses' menu') to ('two') indicates the number of courses that constitute the parts of the whole referred to by $\mathrm{N}_{2}$, in this case menu. The fact that CGs express meronymy, crucially relates them semantically to DGs, which have meronymy as one of their core semantic meanings, cf. examples like: husets tag ('the house's roof'), moengdens tal ('the set's numbers') etc. However, while for DGs both the Constitutive and the Agentive qualia roles are relevant, only the constitutive role comes into play with CGs (hence my choice of the term 'constitutive genitives'). Based on his analysis of the formal semantics of constitutive nouns and, more generally, countable nouns, Jensen (2017)

12 Using a concept of 'rank' originally conceived by Jespersen (1924:96). 
lays out a proposal as to how the semantic composition of CGs may take place, e.g. for en to retters menu, the result comes out as ):

(8) $\lambda \mathrm{P}[\exists \mathrm{x}, \mathrm{y}$ (course' $(\mathrm{y}) \Lambda$ number'(y) $=2 \Lambda$ menu'(x) $\Lambda$ has_part'(y)(x) $\Lambda$ part_of' $(\mathrm{x})(\mathrm{y}) \Lambda \mathrm{P}(\mathrm{x}))]$

This concludes my summary account of the semantics of the subcategories of pre-nominal genitive types in the chart in ). In the following section, I present a thorough overview of all relevant data pertaining to the syntactic and semantic differences between DGs and QGs.

\section{The essential data set:}

Distinguishing determiner genitives from quantity genitives in Danish

This section presents in a tabular form the syntactic and semantic characteristics of Danish DGs and QGs. The characterization of QGs relies on the argument set out in Jensen (2017). ${ }^{13}$ As regards the syntax of Danish DGs, I consider it very much an open issue, to which I return in section 5.

Table 1: Syntactic and semantic characteristics of Danish DGs and QGs.

\begin{tabular}{|c|c|c|}
\hline & Determiner Genitives (DG) & Quantity Genitives (QG) \\
\hline & $\begin{array}{l}\text { Attributive APs following DG s must } \\
\text { take the definite form. } \\
\text { Bo s gode digt } \\
\text { Bo GEN good }{ }_{\text {[DEFINITE] }} \text { poem } \\
\text { Bo s } \text { *godtdigt }_{\text {go GEN good }} \text { [INDEFINITE] poem } \\
\text { 'Bo's good poem' }\end{array}$ & 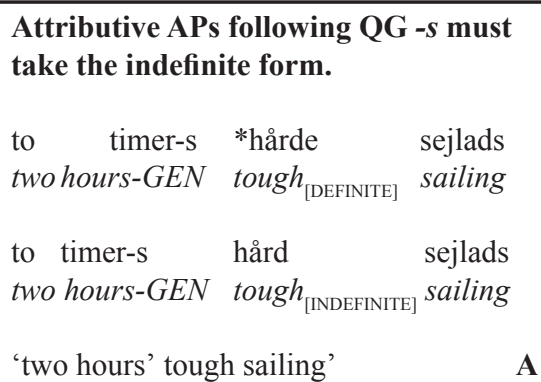 \\
\hline
\end{tabular}

${ }^{13}$ The bold-faced letters $\mathbf{A}$ and $\mathbf{U}$ in the bottom right-hand corner of each cell in the QGcolumn respectively indicate whether the item is $[A]$ nalysed or [U]nanalysed in Jensen (2017). 


\begin{tabular}{|c|c|c|}
\hline 2 & $\begin{array}{l}\text { DGs may be substituted by } \\
\text { possessive pronouns. }{ }^{14} \\
\frac{\text { drengen s hårde sejlads }}{\text { 'the boy's tough sailing' }} \\
\frac{\text { hans }}{\text { 'his tough sailing' }}\end{array}$ & $\begin{array}{l}\text { QGs may not be substituted by } \\
\text { possessive pronouns. } \\
\begin{array}{ll}\frac{\text { to timer-s }}{\text { 'two hours' }} \quad \begin{array}{l}\text { hård } \\
\text { tough }\end{array} & \begin{array}{l}\text { sejlads } \\
\text { sailing' }\end{array} \\
\text { *deres hård sejlads } \\
\text { 'their tough sailing' }\end{array}\end{array}$ \\
\hline 3 & $\begin{array}{l}\text { Stacked DGs cannot permute } \\
\text { preserving meaning. } \\
\text { (i) denne elev s lærer s brev } \\
\text { 'this pupil 's teacher's letter' } \\
\text { (ii) denne lærer s elev s brev } \\
\text { 'this teacher's pupil's letter' } \\
\text { (i) } \neq \text { (ii) }\end{array}$ & $\begin{array}{l}\text { Stacked QGs may permute preserving } \\
\text { meaning. } \\
\text { (i) } 60 \text { kvadratmeter-s to værelser-s } \\
\text { lejlighed } \\
\text { ' } 60 \text { square metres' two rooms' flat' } \\
\text { (ii) to værelser-s } 60 \text { kvadratmeter-s } \\
\text { lejlighed } \\
\text { 'two rooms' } 60 \text { square metres' flat' } \\
\text { (i) = (ii) }\end{array}$ \\
\hline 4 & $\begin{array}{l}\text { DG } \boldsymbol{s} \text { rankshifts } \mathbf{N}_{\mathbf{1}} \text { into a determiner. } \\
\text { (i) *en bil tag } \\
a \quad \text { car roof } \\
\text { (ii) en bil s tag } \\
\text { a car GEN roof } \\
\text { 'a car's roof' }\end{array}$ & $\begin{array}{l}\text { QG -s rankshifts } \mathbf{N}_{1} \text { into an attributive } \\
\text { adjectival }{ }^{15} \text { allowing it to intersperse } \\
\text { with APs. } \\
\text { (i) } 140 \text { kilometer-s flot solokørsel } \\
140 \text { kilometer-GEN great solo ride } \\
\text { (ii) flot } 140 \text { kilometer-s solokørsel } \\
\text { great } 140 \text { kilometer-GEN solo ride } \\
\text { 'great } 140 \text { kilometers'solo ride' }\end{array}$ \\
\hline 5 & $\begin{array}{l}\text { All DGs have the same syntactic } \\
\text { structure }\end{array}$ & $\begin{array}{l}\text { All QGs have the same syntactic } \\
\text { structure }\end{array}$ \\
\hline
\end{tabular}

14 Whilst this description is received wisdom in most analyses of DGs, including generative ones, it is challenged by by Vikner (2012) and Vikner (2014); therefore I cannot claim my formulation of this item to be theoretically neutral. For further discussion, see sections 5 and 6 below.

15 More specifically, QG-s attaches to members of the class of quantity nouns identified by Jensen (2017). 


\begin{tabular}{|c|c|c|}
\hline 6 & $\begin{array}{l}\text { DGs with part-whole-interpretation } \\
\text { have the whole-denoting nominal } \\
\text { preceding } \mathbf{s} \text {. } \\
\text { pigen } \mathrm{s} \text { arm } \\
\text { girl-the GEN arm } \\
\text { 'the girl's arm' }\end{array}$ & $\begin{array}{l}\text { Constitutive genitives have the part- } \\
\text { denoting nominal preceding -s. } \\
\text { to retter-s menu } \\
\text { two courses-GEN menu } \\
\text { 'two course menu' }\end{array}$ \\
\hline 7 & $\begin{array}{l}\text { DG } s \text { attaches to the rightmost } \\
\text { phonetically realised word form of } \\
\mathbf{N}_{1} \text { independently of the word class of } \\
\text { this word form. } \\
\text { manden med hatten s søn } \\
\text { man-the with hat-the GEN son } \\
\text { 'the man with the hat's son' }\end{array}$ & $\begin{array}{l}\text { QG -s must attach to a preceding } \\
\text { quantity noun }{ }^{16} \text {. } \\
\text { (i) to timer-s rejse } \\
\text { two hours-GEN journey } \\
\text { (ii) * to timer med båd-s rejse } \\
\text { two hours by boat-GEN journey }\end{array}$ \\
\hline 8 & & 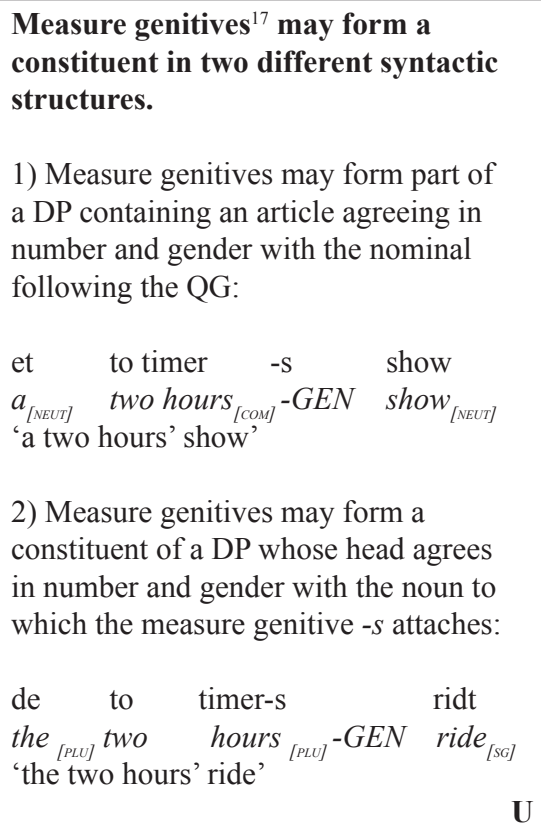 \\
\hline
\end{tabular}

${ }^{16}$ Cf. the classification proposed by Jensen (2017, sect. 4.2).

17 But apparently not constitutive genitives, which allow only the first structure, i.e. (i):
(i) et to motorer-s fly
$a_{[N E U T]}$ two engines ${ }_{[\mathrm{COM}]}-G E N$ plane [NEUT]

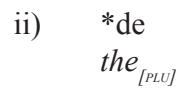
to
two
motorer-s
engines $_{[P L U]}-G E N$
godt fly
$\operatorname{good}_{[s G]}$ plane $_{[s G]}$ 


\begin{tabular}{|c|c|c|}
\hline 9 & 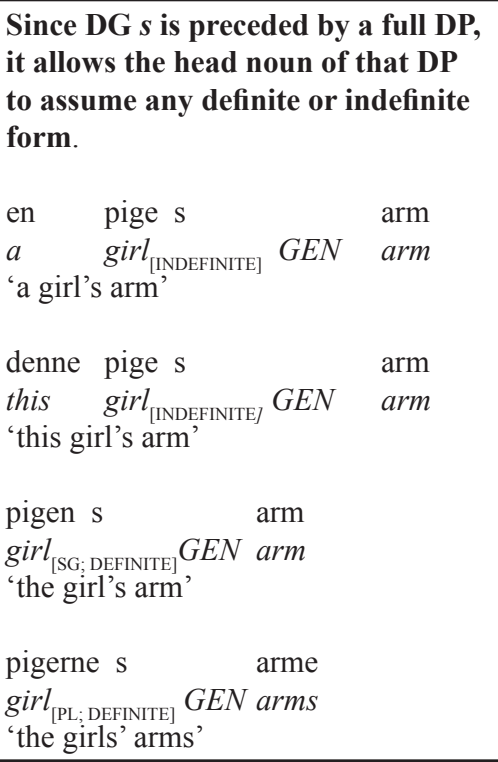 & 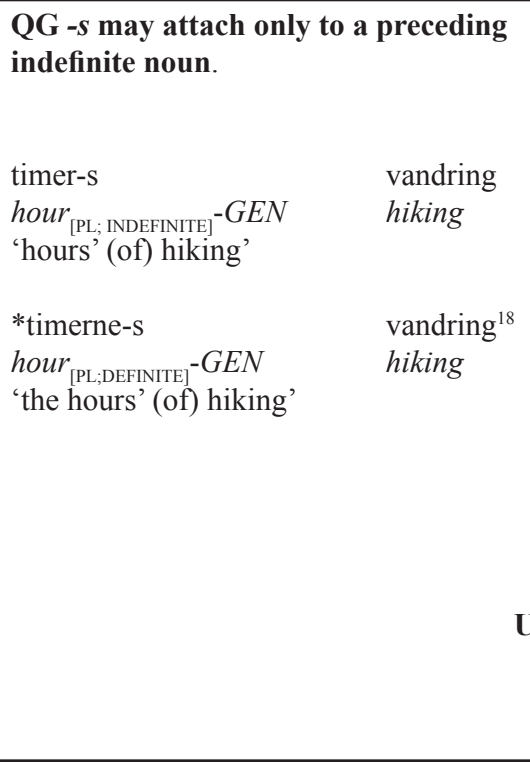 \\
\hline $\begin{array}{l}\text { Seman- } \\
\text { tics } \\
10\end{array}$ & $\begin{array}{l}\text { DG } s \text { requires a relation from } \mathbf{N}_{2} \text {, } \\
\text { and } \mathbf{N}_{1} \text { delivers an argument to that } \\
\text { relation. } \\
\text { (i) Relational nouns provide the } \\
\text { genitive relation directly from their } \\
\text { argument structure. } \\
\text { (ii) Sortal nouns pick up a relation } \\
\text { from an available qualia role: The } \\
\text { agentive role yields a producer } \\
\text { relation; The constitutive role yields a } \\
\text { part-whole relation. } \\
\text { (iii) DG } s \text { may itself deliver a 'control' } \\
\text { relation. }\end{array}$ & $\begin{array}{l}\text { Measure genitives denote only } \\
\text { measure. } \\
\text { to timer-svandring } \\
\text { two hours-GEN hiking } \\
\text { 'two hours' hiking' }\end{array}$ \\
\hline 11 & & $\begin{array}{l}\text { Constitutive genitives denote measure } \\
\text { and provide the part-term of a part- } \\
\text { whole relation. } \\
\text { tre retter-s } \\
\text { three courses-GEN menu } \\
\text { 'three course menu' menu }\end{array}$ \\
\hline
\end{tabular}

18 Notice that the reading here is not with timerne ('the hours') as subject. That would constitute a DG, not a QG, cf. timernes langsomme vandring ('the hours' slow wandering'), where langsomme is the definite singular form of the adjective langsom ('slow').

19 For a formal semantic account of this theory for English, but also valid for Danish, see Vikner \& Jensen (2002). 


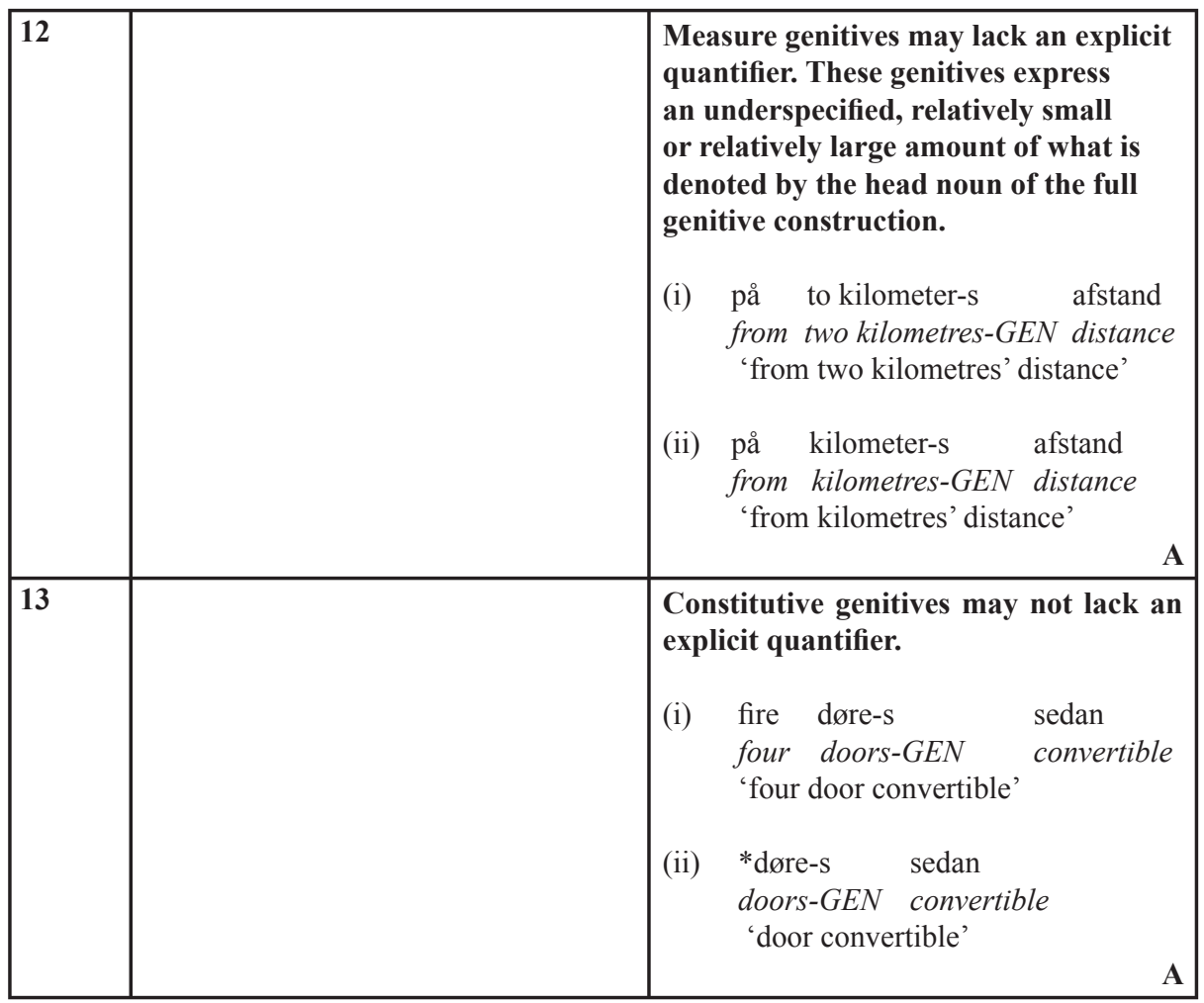

This concludes my presentation of the essential data set showing the differences between DGs and QGs.

\section{A DP analysis of Danish determiner genitives}

Even though a tremendous amount of energy has been spent trying to account for genitive syntax and semantics across languages, as far as Danish is concerned, quite a few problems still need solving. An important first step is to understand the challenges raised by each item in Table 1. The following section is dedicated to initiating that task. Due to space limitations, only a tiny selection of the challenges can be addressed here. I have therefore chosen to focus on selected issues related to a chomskyan DP-analysis of Danish DGs, indeed, the only serious attempt to understand Danish DGs in a P\&P framework, viz. Vikner (2012) and Vikner (2014). The latter is, by and large, a Danish version of the former, and both papers are rejoinders to Jensen (2012). Vikner proposes the following syntactic structure for Danish a DG like en mands tegnebog ('a man's wallet'): 


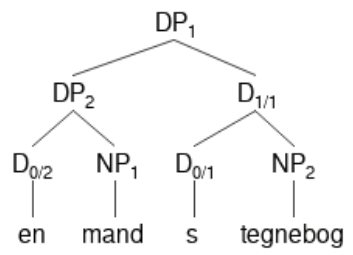

This structure says that $\mathrm{DP}_{1}$ is headed by $s$, indicated by the subscript added to the category $\mathrm{D}_{0}$. In the specifier position sits another full nominal, $\mathrm{DP}_{2}$, headed by $\mathrm{D}_{0 / 2}$, the indefinite article en ('a').

\section{Some challenges for Vikner's DP analysis of Danish determiner genitives}

In this section, I shall discuss selected aspects of Vikner's DP-analysis including the crucial assumption of a constituent like $\left[{ }_{D}, s\right.$ tegnebog] (“ 's wallet'), which is unique in that the DP projected from $\left[_{D} s\right]$ turns out to be ungrammatical in all syntactic contexts in the language. No other constituent exhibits that behaviour. I shall address a number of issues which are less familiar but firmly rooted in the set of Danish data in Table 1: Definiteness in DGs and attributive APs (cf. item 1); DG substitutability by possessive pronouns (cf. item 2); and finally DG $s$ and cliticization (cf. item 7). I wrap up each subsection below with a number of questions raised in my discussion of the DP-analysis. I should add that I certainly do not have answers to all of them myself.

\subsection{DGs and definiteness}

The question of definiteness in Danish DGs is extremely intriguing. Vikner's papers do not address these issues, but they are well worth pursuing when trying to assess the merits of his DP-analysis.

'Internal'and 'external'definiteness in Danish DGs. Any theory of Danish pre-nominal genitives must be able to account for the definiteness feature of attributive APs following $s$. Jensen (1994) is the first to demonstrate that there are two independent definiteness 'systems' involved in DGs: one pertains to the DG internally, called 'internal definiteness', and the other concerns the external syntactic behaviour of DGs, in particular, their behaviour in der-constructions ('there-constructions); this feature he 
calls 'external definiteness'. The 'internal definiteness' of DGs is seen in examples like 0), where we observe the definite form of the attributive AP:
a. en mand $\mathrm{s}$ fede
tegnebog
a man GEN fat ${ }_{\text {[DEFINITE] }}$
wallet
b. en mand $\mathrm{s} \quad *_{\text {fed }}$
a man GEN fat ${ }_{\text {[INDEFINITE] }}$
tegnebog
wallet
'a man's * fat wallet'

The 'external definiteness' of DGs is in evidence in der-constructions like $1)$ :

a. der lå [en mand $\mathrm{s}$ tegnebog] i Melora $\mathrm{s}$ sengebord

there lay a man GEN wallet in Melora GEN

bedside cabinet

'there lay a man's wallet in Melora's bedside cabinet'

b. *der lå [mand-en s tegnebog] i Meloras

sengebord

there lay man-the GEN wallet in Melora.GEN

bedside cabinet

'there lay the man's wallet in Melora's bedside cabinet'

I shall start by looking at the external definiteness.

'External definiteness' and DP-heads. Danish der-constructions strongly select indefinite over definite nominals. This accounts for the acceptability pattern in ). The only difference between the authentic example in a) and the constructed one in b) is that the indefinite article en ('a') in a) has been substituted by the definite suffix -en ('-the') in b). This shows that it must be the indefinite article that single-handedly determines the external definiteness of the DP en mand s tegnebog ('a man's wallet').

Now, take a closer look at Vikner's DP-structure ${ }^{20}$ for en mands tegnebog repeated here as 2):

20 Modelled on the DP-structure schema in Vikner (2014: 198, ex. (18)). 
No one would probably dispute that $\mathrm{DP}_{2}$ is indefinite because it necessarily

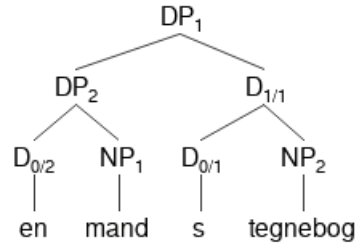

inherits its definiteness value from the indefinite singular common gender article en. By the same token, it ought to follow that $\mathrm{DP}_{1}$ inherits its definiteness value from its head, $s$. But, as I have demonstrated in ), it is the article $\mathrm{D}_{0 / 2}$ in $\mathrm{DP}_{2}$ that determines the definiteness value also of $\mathrm{DP}_{1}$, not $s$ ! In fact, $s$ seems to have nothing to do with the definiteness of $\mathrm{DP}_{1}$. The DP analysis in ), therefore, needs to answer the following question: By what principle does a DP inherit definiteness from its DP-specifier, when the definiteness of a DP usually percolates from its head, $\mathrm{D}_{0}$ ? It seems, then, that $s$ does not behave like other members of the category $\mathrm{D}$, in particular, articles and demonstratives like en ('a'), den ('the'), denne ('this') etc. So, what is DG $s$ doing in that category?

What does it mean that $\mathbf{s}$ is $\boldsymbol{a} \mathbf{D}$ ? An old saying goes: "If it looks like a duck, walks like a duck and talks like a duck, it probably is a duck!" Now, what if it doesn't? Talking about animals, I'd like to claim that $s$ looks much more like a platypus than it does a duck. In addition to the empirical evidence on external definiteness already presented, there is more to back up the view that DG $s$ has nothing whatsoever in common with other members of the category D. Compare an assumed lexical entry for $s$ to partial lexical entries for the articles en ('a) and det ('the'):

en:

det:

$\begin{array}{lll}\text { CAT }=\text { D } & \text { CAT }=\text { D } & \text { CAT }=\text { ? } \\ \text { NUM }=\text { sg } & \text { NUM }=\text { sg } & \text { NUM }=\text { ? } \\ \text { GEN }=\text { com } & \text { GEN }=\text { neut } & \text { GEN }=\text { ? } \\ \text { DEF }=\text { indef } & \text { DEF }=\text { def } & \text { DEF }=?\end{array}$

The question marks in the entry for $s$ indicate that all the feature values which typically characterize members of the determiner category are void for $s$. Thus, there is no empirical support for the alleged paradigmatic relation of $s$ to the standard members of the category D. Due to space 
limitations, I cannot go into the semantic differences which should also be part of the entries in ), but my brief remarks on the semantics of DG $s$ in section 3 should give a hint that the differences between the intricate relational semantics of $s$ and the semantics of standard determiners are huge.

So, the next question the DP-analysis needs to answer, is this: What makes $s$ qualify for paradigmatic membership of the category D? I now return to the question of the 'internal definiteness' and attributive APs in DGs.

The 'internal definiteness' of DGs. Recall that the internal definiteness of DGs concerns the definite form of possible attributive AP-modifiers. Apart from the provisional DEF-subscripts I have added to the AP and NP constituents, Vikner (2014) would assign the structure in (14) to Bo s gode digt ('Bo's good poem'):

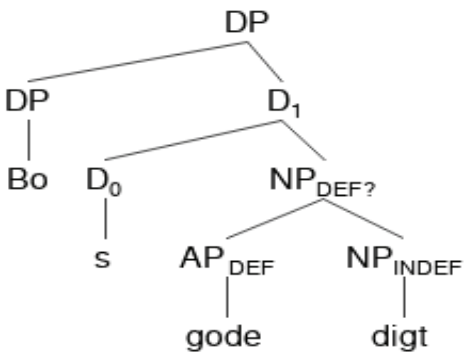

The added subscripts indicate respectively that gode is indisputably the singular definite form of the adjective god, digt is indisputably the singular indefinite form of the noun digt, and the 'DEF?' subscript on NP indicates a possible problem here.

Under standard definitions of $c$-command, $m$-command and government ${ }^{21}$, the structure in (15) might seem to support the DP-analysis of DGs. In (15), $s$ governs its NP complement. It would therefore seem that $s$ may directly impose the definite form on the AP inside its complement.

21 See e.g. https://en.wikipedia.org/wiki/Government_and_binding_theory\#Government and the references there. 
However, subcategorization is not about requiring a certain form of a modifier inside a complement. Subcategorization is strictly about the form of the complement, e.g. its syntactic category or the phonetic form of its head without regard to any modifiers, whose occurrence is, by definition, unpredictable.

So, could it be that the definiteness of the AP-modifier is an indirect consequence of $s$ requiring not only that the syntactic category of its complement be NP, but also that it be definite? If that were the case, one might argue that the attributive AP agrees with the N-head of $s$ 's complement and the two NP nodes forming the adjunction. Unfortunately, the head of the NP complement digt ('poem') in (15) is not definite, and therefore the NPs cannot be either. In sum, there can be no definiteness requirement imposed by DG $s$ on its complement NP. On top of that, Danish (unlike Norwegian and Swedish) does not allow definiteness agreement between head and modifier. This is hard evidence that the definite form of the AP comes neither from the NP dominating it nor from its NP sister node. It seems that the definiteness has to trickle down to the AP only, not affecting any of its adjacent NP nodes. I therefore sincerely doubt that the definiteness of the attributive AP can be an effect of subcategorization, i.e. complement government.

One last possibility one might consider, is that definiteness agreement holds between DG $s$ and the attributive adjective. In other words, let's assume that $s$ is specified as definite in its lexical entry, and that the attributive AP agrees with $s$. Since, according to the DP-analysis, $s$ belongs to the same category as definite articles and demonstratives like den ('the ${ }_{\text {[ART; COMMON] }}$ ') and dette ('this ${ }_{\text {[DEM; NEUTER] }}$ '), this proposal does not seem at all unreasonable because in Danish both articles and demonstratives do indeed agree with attributive APs wrt. definiteness, cf. 15):
a. det
gode
digt
the
[DEFINITE] $\operatorname{good}_{\text {[DEFINITE] }}$
'the good poem'
poem $_{\text {[INDEFINITE] }}$
b. et
godt
digt
$a_{\text {[INDEFINITE] }} \operatorname{good}_{\text {[INDEFINITE] }}$
poem $_{\text {[INDEFINITE] }}$
'a good poem'

Therefore, we might hypothesize a similar pattern for $s$ as indicated in 6): 
(16)

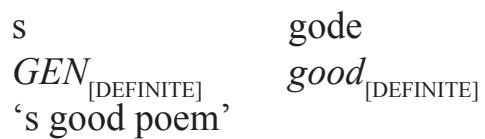

digt

poem $_{\text {[INDEFINITE] }}$

Apart from the well-known fact that $s$ gode digt works terribly badly as a constituent, the problem at hand is yet another serious one: The thing is that if $s$ is definite, the DP projected from it must necessarily inherit that definiteness, which will cause a dreadful clash with the indisputable indefiniteness of the DP it projects in examples like ), en mand s tegnebog ('a man's wallet'). Once again, we note the remarkable platypus-ness of DG $s$ compared to the ducks in the D-pen. Thus, the next question for the DP-analysis of DGs is this: What is the principled explanation of how the DP-analysis accomplishes this definiteness assignment to attributive APs? ${ }^{22}$

\subsection{Substitutability of genitives by possessive pronouns}

The observation that DGs, but never QGs, are substitutable by possessive pronouns, is due to Mikkelsen $(1911, \S 86 / 254)$. Despite its considerable seniority, this seminal observation has been completely overlooked in subsequent Danish grammatical literature, even by authoritative reference grammars like Diderichsen (1946) and Hansen \& Heltoft (2011). ${ }^{23}$

But what is pronominal substitution about, then, particularly in relation to phrase structure grammar and its notion of constituency? A recent, in-depth study of this topic is Osborne (2018), which covers most of the available literature on the subject. One statement representative of Osborne's conclusions is this: "Pronominalization [...] provides us with further evidence for phrases. This is because proforms replace phrases, rather than heads, and are thus words that 'stand for' phrases" (Lobeck, 2000: 53). The use of terms like 'pro-NP', 'pro-VP', and 'pro-DP' reflects this view of the process of pronominal substitution of phrases. Thus, one

22 Since this paper addresses both DGs and QGs, a brief remark on the definiteness of QGs is in order here. According to Jensen (2017: 51), QGs belong to a syntactic type which functions exactly like an AP pre-modifier. Thus, QG -s does not affect the definiteness of adjacent adjectival modifiers, and Jensen's hypothesis about the definiteness of QGs and APs should cause no problems for a DP-analysis (cf. Delsing 1993 sect. 3.2.2 and Platzack, 1998, sect. 8.4.2). Note that QGs do not belong to the phrasal category AP since they are not headed by an adjective. The head of a QG is QG -s, which belongs to the singleton category GQ, for details, see Jensen (2017, sect. 3.3).

For a thorough discussion, see Jensen (2017). 
would not expect it to be possible to have pronominal substitution of the individual words in the bracketed part of $7 . a$ ):

a. [en dreng s] gode digt 'a boy's good poem'

b. [ hans ] gode digt 'his good poem'

On the other hand, the construction en dreng $s$ ('a boy's') would be a prime candidate for a constituent since it is substitutable by the possessive pronoun hans ('his') as illustrated in 7.b). However, this analysis is challenged by Vikner, who analyses the examples in 7) as shown in 8), where hans does not substitute for en dreng $s$, but only for $s$ :
a. en dreng $\quad\left[\mathrm{D}_{0} \mathrm{~s} \quad\right]$ gode digt 'a boy's good poem'
b. $[$ D hans $]$ gode digt 'his good poem'

According to Vikner, then, even though he makes a point of the fact that e.g. personal pronouns like English he and one do replace full phrases like DP and NP (see Vikner 2012:3), possessive pronouns belong to the category $\mathrm{D}_{0}$ and do not substitute for phrases but for a single lexical item which could never form a phrase on its own. Thus, in his analysis en dreng $s$ ('a boy 's') forms neither a constituent nor a phrase, whereas $s$ gode digt (GEN good poem; i.e. 's good poem') does. This means, of course, that we can no longer use possessive pronouns for phrasal substitution tests like all other pronouns. The upshot is that this DP-analysis sends most of the time-honoured methodological deliberations on pronominalization and constituency in phrase structure grammars down the drain.

In his analysis in ), Vikner calls hans a possessive pronoun, while according to his own definition ${ }^{24}$ - "determiners have NP complements, pronouns do not" - hans looks much more like a possessive determiner. Either way, he has now introduced a novel category into the grammar: a 'pro- $\mathrm{D}_{0}$ ', which is clearly referential in its semantics, but which substitutes for an absolutely non-referential lexical item: $s$. Furthermore, this analysis disowns Mikkelsen's important discovery, which makes it

24 Cf. Vikner (2014: 196). 
immediately transparent that if hans substitutes for en dreng $s$, one gets the referential semantics for free, and, there can be no doubt that we need the male-sex pronoun hans rather than the female-sex pronoun hendes ('her'), for instance. What we gain by letting hans substitute for $s$ is, at best, unclear as far as referentiality is concerned.

Three further questions to the DP-analysis have now appeared: Why do possessive pronouns behave differently from all other pronouns with respect to phrasal substitution? Is it methodologically satisfactory to claim syntactic substitutability between syntactic items with referential import like pronouns and non-referential single lexical items like DG $s$ ? How is the referent of a pro- $\mathrm{D}_{0}$ like hans ('his') semantically retrieved?25

\subsection{DG $s$ and cliticization}

Most modern treatments of Danish DGs assume that $s$ is involved in a process of cliticization with respect to its preceding nominal, $\mathrm{N}_{1}$. This assumption seems like an intuitively reasonable consequence of two things: First, the fact that /s/ cannot stand on its own due to rules of Danish phonology, and therefore has to find a host to lean to in order to create a legitimate phonological word form. Second, due to the traditionally accepted substitutability of constructions like en dreng $s$ ('a boy's') by a possessive pronoun, the assumption is that $\mathrm{N}_{1}$ is a complement or, at least, a syntactically close dependent of $s$.

For Vikner (2014) a more complex process is involved. In the DPanalysis, $s$ is not in a phrasal construction with the specifier to which it supposed to cliticize, and according to P\&P-theory heads cannot place syntactic requirements on their specifiers. It is therefore unclear what should theoretically allow $s$ to enter into some kind of structure with $\mathrm{N}_{1}$. Vikner mentions that clitics are also known from Romance languages, and he further suggests that $s$ may behave somewhat like the English clitic negation $n ' t$. He claims that $n^{\prime} t$ seems to select the category of its host, which should account for the acceptability of [does]n't vis-à-vis the unacceptability of *[John]n't.

For two reasons, I'm rather skeptical about Vikner's analysis: First, couldn't the unacceptability of *[John]n't simply follow from the straightforward semantic fact that one cannot meaningfully deny a physical object, but only the occurrence of an event or the truth value of a

$\overline{25}$ I'm aware that c-command requirements are met, but that does not explain how one gets the semantics right as when one assumes phrasal substitution. 
proposition? Second, in their seminal work on clitics, Zwicky \& Pullum (1983: 503) argue that English $n$ 't is like an affix, not a clitic. Their analysis is that affixes attach to words they are connected to semantically and to a particular part of speech, whereas clitics "exhibit a low degree of selection with respect to their hosts". I think, when one chooses to bring in data from other languages into one's argument, as Vikner does here, one has a very strict obligation to argue how the phenomena brought in are similar to the item investigated. I do not see any similarity between Romance clitic pronouns and DG $s$, even less between DG $s$ and English $n$ 't, and between Romance clitic pronouns and the English contracted negation $n$ 't there is no similarity, either. Further, the analysis of $n$ 't as a clitic doesn't seem to hold up under closer scrutiny. So, bringing together Romance clitic pronouns, elements like English $n$ 't and Danish DG $s$ in one argument is, in my opinion, methodologically unsound.

Yet another thing bothers me about the relationship of DG $s$ to its specifier under a DP-analysis: It follows from the analysis of possessive pronouns as belonging to the category D that they project full DPs. The theory therefore erroneously predicts the grammaticality of expressions like 19) with structures like (20):
a. *min $\mathrm{s}$ bil 'my's car'
b. *hans $\mathrm{s}$ bil
'his 's car'

(20)

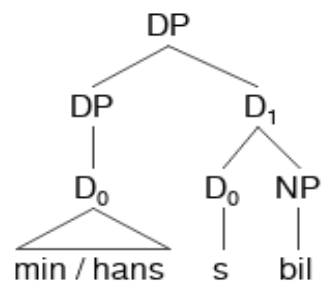

It is a mystery to me factually, syntactically, semantically and cliticizationally what is supposed to be going on here. 


\section{Conclusion}

On the basis of the methodological and theoretical stances of Noam Chomsky, Otto Jespersen and Kristian Mikkelsen, I have charted the landscape of Danish pre-nominal genitives and described in detail the syntactic and semantic differences between determiner genitives and quantity genitives. I have tried to present the differences neutrally, not relying on theoretical assumptions. Based on a small selection of the data, I have addressed a number of issues raised by a DP-analysis of determiner genitives proposed by Sten Vikner (2014). In particular, I have demonstrated how Vikner's proposal runs into problems explaining the patterns of definiteness, pronominalization, referentiality and cliticization. The overall conclusion of this discussion is that the DP-analysis is less than convincing. Further, the method of mixing disparate data from different languages in the argumentation is a cause for concern.

\section{References}

Borschev, Vladimir \& Barbara, H. Partee. 2000. Genitives, relational nouns, and the argument-modifier distinction. ZAS Papers in Linguistics. 177-201.

Briscoe, Ted, Ann Copestake \& Branimir Boguraev. 1990. Enjoy the paper: Lexical semantics via lexicology. In Hans Karlgren (ed.), Papers presented to the 13th International Conference on Computational Linguistics, vol. 2, 42-47. Helsinki.

Chomsky, Noam A. 1957. Syntactic structures. The Hague: Mouton.

Chomsky, Noam A. 1964. Current issues in linguistic theory. The Hague: Mouton.

Chomsky, Noam A. 1965. Aspects of the theory of syntax. Cambridge, MA: MIT Press.

Chomsky, Noam A. 1975. The logical structure of linguistic theory. New York: Plenum.

Delsing, Lars-Olof. 1993. The internal structure of noun phrases in the Scandinavian languages. $\mathrm{PhD}$ thesis. Lunds Universitet.

Del Pinal, Guillermo. 2015. The structure of semantic competence: Compositionality as an innate constraint of the faculty of language. Mind \& Language. 30(4): 375-413. doi:10.1111/mila.12084.

Diderichsen, Paul. 1946. Elementcer Dansk Grammatik. København: Gyldendal.

Gazdar, Gerald, Ewan Klein, Geoffrey Pullum \& Ivan Sag. 1985. Generalized phrase structure grammar. Cambridge, MA: Harvard University Press.

Hansen, Erik \& Lars Heltoft. 2011. Grammatik over det danske sprog, bind 1-3. København: Det Danske Sprog- og Litteraturselskab. 
Jensen, Per Anker. 1994. Genitive phrases in Danish. In Michael Herslund (ed.), Noun phrase structures. Copenhagen Studies in Language 17, 47-92 København: Samfundslitteratur.

Jensen, Per Anker. 2012. Genitiv-syntaks: Er s et D eller et G? Ny Forskning $i$ Grammatik 19. Odense: Syddansk Universitetsforlag. 105-128.

Jensen, Per Anker. 2013. Danske kvantumsgenitivers position i DP-strukturen. Ny forskning i grammatik 20. 163-181.

Jensen, Per Anker. 2014. Mikkelsens tillægsfald i et generativt perspektiv. In Ole Togeby, Sten Vikner, \& Henrik Jørgensen (eds.), Problemer og perspektiver $i$ dansk syntaks. Universitets-Jubilæets danske Samfunds skrifter nr. 585. Odense: Syddansk Universitetsforlag. 62-89.

Jensen, Per Anker. 2017. De danske kvantumsgenitivers syntaks og semantik. Nydanske sprogstudier 52-53. 39-78.

Jensen, Per Anker \& Carl Vikner. 1994. Lexical knowledge and the semantic analysis of Danish genitive constructions. In Steffen L. Hansen \& Helle Wegener (eds.), Topics in knowledge-based NLP systems, 37-55. København: Samfundslitteratur.

Jensen, Per Anker \& Carl Vikner. 2004. The English prenominal genitive and lexical semantics. In Ji-yung Kim, Yuri A. Lander \& Barbara H. Partee (eds.), Possessives and beyond: Semantics and syntax. 29. 2-27. University of Massachusetts occasional papers in linguistics: Amherst, MA.

Jespersen, Otto. 1924. The philosophy of grammar. London: George Allen \& Unwin.

Jespersen, Otto. 1937. Analytic syntax. Copenhagen: Levin \& Munksgaard. Ejnar Munksgaard.

Krifka, Manfred. 1989. Nominal reference, temporal constitution and quantification in event semantics. In Renate Bartsch, Johan van Benthem \& Peter van Emde Boas (eds.), Semantics and contextual expressions, 75-115. Dordrecht: Foris.

Lobeck, Anne. 2000. Discovering grammar: An introduction to English sentence structure. New York: Oxford University Press.

Löbner, Sebastian. 2011. Concept types and determination. Journal of Semantics 28(3)

https:/www.philfak.uniduesseldorf.de/fileadmin/Redaktion/Institute/ Allgemeine_Sprachwissenschaft/Loebner/Loebner_ConceptTypes

Determination_preprint.pdf. (November 2, 2018).

Mikkelsen, Kristian. 1911. Dansk ordföjningsloere. København: Hans Reitzels Forlag.

Osborne, Timothy. 2018. Tests for constituents: What they really reveal about the nature of syntactic structure. Language under discussion, vol. 5, issue 1 (April 2018). 1-41. Published by the Language Under Discussion Society. http://www. ludjournal.org/index.php?journal=LUD\&page $=$ article \&op $=$ view\&path $\% 5 \mathrm{~B} \%$ $5 \mathrm{D}=59 \&$ path $\% 5 \mathrm{~B} \% 5 \mathrm{D}=30$. (November 16,2018 ). 
Platzack, Christer. 1998. Svenskans inre grammatik - det minimalistiska programmet. En introduktion till modern generativ grammatik. Lund: Studentlitteratur.

Pustejovsky, James. 1995. The generative lexicon. Cambridge, MA: MIT Press.

Rizzi, Luigi. 2016. The concept of explanatory adequacy. In Roberts, Ian (ed.), The Oxford handbook of universal grammar, 97-113. New York: Oxford University Press. doi:10.1093/oxfordhb/9780199573776.013.5

Sæbø, Kjell Johan. 2018. The explicative genitive and close apposition. Natural Language and Linguistic Theory. doi:10.1007/s11049-018-9421-4.

Vikner, Carl \& Per Anker Jensen. 2002. A semantic analysis of the English genitive. Interaction of lexical and formal semantics. Studia Linguistica 56(2). 191-226.

Vikner, Sten. 2012. Possessors as subjects inside the nominal group: DP-spec vs. GP. Workshop on the similarities and differences between clauses and nominals. University of Aarhus, 14.12.2012.

Vikner, Sten. 2014. Possessorens status inden for nominalgruppen. Ny forskning $i$ Grammatik 21. Odense: Syddansk Universitetsforlag. 193-211.

Zwicky, Arnold M. \& Geoffrey K. Pullum. 1983. Cliticization vs. inflection: English N'T. Language 59(3). 502-513. doi:10.2307/413900. 